\title{
ENSINO DE INOVAÇÃO NA \\ FORMAÇÃO DO ADMINISTRADOR BRASILEIRO: \\ CONTRIBUIÇÕES PARA GESTORES DE CURSO
}

\author{
INNOVATION TEACHING WITHIN THE BRAZILIAN \\ ACADEMIC SCENARIO: CONTRIBUTIONS TO \\ HIGHER EDUCATION COURSE ADMINISTRATORS
}

Recebido em: 14/10/2014 - Aprovado em: 22/12/2014
Avaliado pelo sistema double blind review
Editora Científica: Manolita Correia Lima
DOI: $10.13058 /$ raep.2015.v16n1.202

RAQUEL DA SILVA PEREIRA raquelspereira@uol.com.br

UNIVERSIDADE MUNICIPAL DE SÃO CAETANO DO SUL

\author{
IVALDO DONIZETI FRANCO \\ CENTRO PAULA SOUZA
}

ISABEL CRISTINA DOS SANTOS

UNIVERSIDADE MUNICIPAL DE SÃO CAETANO DO SUL

\author{
ALMIRMARTINS VIEIRA \\ UNIVERSIDADE METODISTA DE SÃO PAULO
}

\section{RESUMO}

Com o objetivo de contribuir para a gestão de negócios inovadores, este artigo investiga como a inovação é abordada nos cursos de Bacharelado em Administração. Este trabalho tem natureza qualitativa apoiada por pesquisa exploratória, com delineamento de pesquisa histórico-documental, com acesso às fontes de dados primários nos bancos de dados do Ministério de Educação e Cultura e do Instituto Brasileiro de Geografia e Estatística, Instituto Nacional de Estudos e Pesquisas Educacionais Anísio Teixeira. A caracterização do contexto brasileiro da inovação foi elaborada com base nos dados do Guide Innovation Index. A análise dos dados permitiu identificar os diferentes estágios do ensino de inovação nos cursos de Administração existentes no país, analisados regionalmente. Como resultados obtidos, aponta-se que, embora minimamente abordado, o tema inovação é mais frequentemente debatido nos cursos de Administração nas regiões sul e sudeste do país, que concentram o maior volume da atividade industrial do país. Este estudo conclui que o tema inovação é pouco debatido nos cursos de Administração, o que indica um espaço de oportunidade de revisão de conteúdo em compasso com as estratégias governamentais para aumento da taxa de inovação nas empresas brasileiras.

Palavras-chave: inovação; educação superior; formação acadêmica do administrador.

\begin{abstract}
With the objective of contributing to innovative business management, this paper investigates how innovation is addressed in Bachelor of Business Administration courses. This work employs a qualitative approach supported by exploratory research and underlined by historical-document research with access to primary data sources in the databases of the Ministry of Education and Culture, Anisio Teixeira National Institute for Studies and Educational Research and the Brazilian Institute of Geography and Statistics. The Brazilian context of innovation was characterized based on the Guide Innovation Index. Data analysis identified the different stages of teaching innovation in existing Administration courses in the country, analyzed regionally. From the results, this paper points out that, although innovation is a marginally addressed topic overall, is most often discussed in Administration courses from Brazil's South and Southeast regions, which account for the majority of the country's industrial activity. This study concludes that the theme of innovation is poorly debated within Brazil's Business Administration courses, indicating an opportunity to review the programmatic contents in line with governmental strategies to increase the rate of innovation in Brazilian companies.

Keywords: innovation; higher education; business administration majoring.
\end{abstract}




\section{INTRODUÇÃO}

A inovação tem sido debatida pelo governo brasileiro como uma importante estratégia de desenvolvimento da competitividade nacional. É fato que os países que aspiraram inclusão no seleto grupo de países industrialmente desenvolvidos fizeram uma opção pela transição do modelo econômico, eventualmente baseado em atividades do setor primário da economia, para a economia industrial baseada na geração de produtos com conteúdo tecnológico. Essa transição de modelo foi viabilizada pela reorientação dos investimentos públicos para o fortalecimento da educação, em setores considerados estratégicos ao desenvolvimento nacional e potencialmente geradores de novas indústrias. A Coréia do Sul é um exemplo consagrado pela literatura atual (LUZ; SANTOS, 2007; KIM; NELSON, 2008).

Embora passível de controvérsias, a reforma no sistema público de educação sul-coreano, em meados da década de 1990, estabeleceu como driver educacional a orientação dos conteúdos programáticos e, ao longo prazo, das carreiras, baseada nas demandas de mercado. Houve, inclusive, aumento da autonomia das escolas para adequação dos programas. Assim, o neoliberalismo alcançou o tradicional e burocrático modelo de ensino público, oferecendo diversidade e possibilidade de escolhas substantivas dos indivíduos, ao mesmo tempo em que, vocacionados, estes e o sistema educacional como um todo fortaleceram a competividade nacional. Deixando de lado a padronização dos conteúdos e carreiras em benefício da autonomia das instituições, a controvérsia se deu em torno das preocupações descritas por Oh (20II, p. 38I), em relação ao risco de serem criadas: uma indesejável competição por desempenho e reconhecimento do mercado entre as escolas; associação entre o nome da escola e o status social dos seus alunos, e, por isso, a geração de desigualdades de oportunidades de aprendizagem e exclusão social.

A reforma educacional não aponta somente na direção dos estudantes. Pelo contrário, a maioria dos países que pretendem atingir crescimento econômico e o reconhecimento em nível mundial voltaram seus olhares sobre a reforma da educação, inclusive da profissão de professor, orientada 
no sentido do aumento da mobilidade social proporcionada pela carreira e tendo os professores como elementos-chave para alcançar a educação de qualidade (GOODWIN, 20I4, p. I85).

A associação entre desenvolvimento econômico, inovação e elevação da qualidade do ensino, e da cultura, em todos os níveis, é inevitável. Especialmente, quando se vislumbra um modelo econômico fortemente pautado na ampliação da capacidade industrial de um país. Esse entrelaçamento entre os termos apresentados vem sendo discutido no escopo da criação de uma Política Nacional de Ciência e Tecnologia por diversos autores brasileiros nas últimas três décadas. Por exemplo, uma análise feita por Chaves (I979, p. 64), concluía que:

A importância de uma política racional ressalta da necessidade da salvaguarda do desenvolvimento natural das aptidões das melhores inteligências, de modo a evitar desestímulos e desistências, mesmo para prevenir a repetição do fenômeno que já ocorreu entre nós da evasão de cérebros, o "brain-drain", em que os países que não sabem resolver esse problema fundamental se vão empobrecendo cada vez mais dos seus melhores elementos humanos, que se evadem para o estrangeiro e m busca de condições de sobrevivência e de afirmação.

A despeito da passagem de tempo desde a análise feita por Chaves (I979), o empobrecimento da capacidade de alcançar progresso científico, dotando a sociedade de políticas orientadas para o desenvolvimento científico e tecnológico e de recursos humanos cada vez mais qualificados e valorizados, apresenta-se como um fato relativamente atual.

Em outro trecho, Chaves (I979, p. 67) destaca "a necessidade de uma ação coordenadora, e a existência de elementos caracterizadores de uma Política Nacional de Ciência e Tecnologia”.

A ênfase na transição de modelo econômico precedido por uma vigorosa política educacional explica o progresso econômico, gradual e coerentemente, alcançado pelos países asiáticos, como avaliam Luz e Santos (2007, p. I73):

Existem outros aspectos encontrados nos países asiáticos e que não existem no Brasil e que ajudam a explicar os diferentes resultados dos seus esforços 
desenvolvimentistas: estes incluem uma ênfase na educação básica e secundária, o que gera uma força de trabalho competente e bem educada, menores níveis de desigualdade social, desta forma, reforçando o mercado interno para produtos locais, uma clara e inequívoca intenção de incluir nos seus produtos o necessário conhecimento com base nacional, num esforço sustentado na direção de uma competitividade internacional que requer altos níveis de eficiência industrial e controle da qualidade. Deve ser destacado que tais objetivos não podem ser atingidos sem se dispor de serviços públicos competentes e uma burocracia forte trabalhando em íntima associação com algumas firmas grandes e bem administradas.

Ressalta-se que além da capacidade de criação de produtos de alto conteúdo tecnológico, da infraestrutura pública de serviços, é preciso atrair grandes empresas, no padrão world class, e oferecer recursos humanos qualificados, em todas as áreas da atividade pública e privada, visando fortalecer a estrutura de produção, de comercialização de novos produtos e a abertura de novos mercados, para citar alguns fatores considerados na tipologia da inovação (SCHUMPETER, 1982; 1942; DRUCKER, 1998; SIMANTOB; LIPPI, 2003; MANUAL DE OSLO, 2005; TIDD; BESSANT; PAVITT, 2008). Tais fatores tem uma relação direta com as funções organizacionais de Produção, Vendas e Marketing, o que justifica estabelecer como objeto de estudo do presente artigo, a preparação dos administradores, pelas Instituições de Ensino Superior em Administração, para o enfrentamento das mudanças contínuas no ambiente de negócios e para a gestão de empresas orientadas pela inovação.

Observa-se que o Governo Brasileiro tem, nas últimas duas décadas, dirigido importantes esforços para estimular a inovação no país. Como exemplos, devem ser mencionados o fortalecimento da estrutura de financiamento à Pesquisa e Desenvolvimento, a criação dos fundos setoriais, implantação da política de parques tecnológicos estaduais e das incubadoras tecnológicas, como lócus de criação, cocriação e inovação e de interação entre governo, universidades e os empreendedores, processo que será discutido ao longo da revisão teórica. Porém, mesmo que a criação de novas empresas tenha o estímulo do governo, a partir da provisão de um 
ambiente inovador e de recursos, constata-se a dificuldade do inventorempreendedor, após a incubação, em desenvolver competências de gestão (SANTOS; KUBO; AMORIM, 20I3), em funções críticas à sustentabilidade econômica e comercial do negócio.

Tumelero (20I2, p. I5), em estudo sobre a sobrevivência das empresas tecnológicas pós-incubadas, destaca que "os empreendedores, especialmente aqueles de formação tecnológica, têm dificuldades de formular e explicitar a estratégia de marketing", mesmo aquelas empresas consideradas inovadoras. $\mathrm{E}$, consequentemente, a competência em estabelecer estratégias de crescimento do empreendimento no longo prazo.

A lacuna no papel do gestor de empreendimentos orientados pela inovação parece estar essencialmente concentrada na atividade de gestão do negócio e não de criação de artefatos e serviços inovadores. Sendo assim, chama a atenção à necessidade de debater o conteúdo da formação da carreira do administrador, para que as competências gerenciais, especificamente orientadas para ambientes inovadores, caracterizados por rupturas e descontinuidades no setor competitivo e no modus operandi, induzindo à adoção de modelos gerenciais pautados pela mudança contínua, e nas interações amplas com o mercado global.

Assim, justifica-se a relevância deste trabalho, que tem como questão de pesquisa examinar de que forma os cursos superiores de Administração incluem o contexto da inovação no conteúdo da formação da carreira? Para respondê-la, definiu-se como objetivo central deste trabalho contribuir para a reflexão acerca da importância da inclusão do tema inovação nos conteúdos programáticos dos cursos de Administração, em nível superior e bacharelado.

Para tanto esta pesquisa investiga as bases de dados do Ministério da Educação e Cultura (MEC), do Instituto Nacional de Estudos e Pesquisas Educacionais Anísio Teixeira (INEP) e do Instituto Brasileiro de Geografia e Estatística (IBGE), a presença de unitermos relacionados à inovação nas matrizes curriculares e nos ementários dos cursos de Administração. Além disso, o artigo considera as características das regiões brasileiras apontadas nos indicadores econômicos e populacionais divulgados pelo IBGE, ao 
analisar a ênfase do ensino da inovação em uma perspectiva regionalmente coerente.

Este artigo está organizado em cinco partes. A primeira apresenta a introdução do trabalho e, brevemente, o contexto que o justifica; a segunda apresenta a fundamentação teórica em que se baseou a pesquisa; a terceira parte apresenta os procedimentos metodológicos aplicados à pesquisa; a quarta parte descreve os resultados obtidos e a discussão teórica; e na quinta parte são formuladas as considerações finais. 


\section{REFERENCIAL TEÓRICO}

Dependendo da conduta de inovação adotada - inovação aberta, parcialmente aberta, ou fechada - as empresas inovadoras costumam combinar a utilização de diversas fontes internas e externas de inovação. Como internas pode-se se considerar programas de melhoria de qualidade, treinamento operacional e aprendizado organizacional. As externas, por sua vez, envolvem a aquisição de informações, livros, revistas, licenças de fabricação, compras de tecnologias (TIGRE, 2006).

Drucker (I998, p. 7) indicou quatro fatores internos à organização, e ao setor da indústria, a partir dos quais surgem as inovações: eventos inesperados, incongruências, necessidades dos processos ou mudanças no mercado ou na própria indústria. Do ponto de vista externo, as inovações adviriam de três fontes de oportunidade: mudanças demográficas; mudanças na percepção, que altera o significado dos objetos; e, por fim, e novos conhecimentos que são, geralmente, portadores de novidades aplicáveis aos produtos e serviços. Todavia, destaca-se o fato de que essas fontes são geradoras de inovação a partir da observação e idealização feita pelos atores dos processos.

Segundo pesquisa de Kearney (2008, p. 7), as fontes internas de inovação respondem por $56 \%$ e as externas respondem por $44 \%$ da geração de novas ideias. Tais ideias advêm, em geral, da observação do cotidiano das operações, da experiência acumulada e da necessidade de aprimorar os processos de trabalho. Neste recorte de análise, destaca-se a importância do papel do gerente como um agente aliado das novas e boas ideias.

A organização European Union for Regional Policy (2009, p. I8) abraça a causa da valorização da criatividade como fonte de inovação, associando-a, porém, ao conjunto de fatores culturais que definem o pulso para a mudança. Citando a estratégia de Lisboa para Crescimento e Emprego, a organização destaca que foram combinadas ações relacionadas ao crescimento econômico com ampliação dos benefícios para a sociedade e para o ambiente, no que definiu como "uma grande estrutura para um negócio vitorioso é construída a partir de ideias. Em negócios, as soluções mais inteligentes sobre produtos são aquelas que permitirão 
melhor desempenho e uma abrangência maior de benefícios". Portanto, é preciso encorajar e valorizar as ideias, constituindo assim, um ambiente favorável à inovação. Este esforço deve ser desempenhado pelos gerentes e líderes de grupo de trabalho.

Ainda, a criatividade é um fenômeno multidisciplinar, um comportamento que busca alternativas de aprimoramento dos resultados esperados, seja do ponto de vista tecnológico ou do meio ambiente que propõe novos resultados e atitudes necessárias neste cenário atual, marcado por uma complexidade crescente e por uma demanda permanente de novas respostas e inovação. Por outro lado, a cultura de aprendizagem e de ensino dominante e massivo, na grande maioria das instituições, privilegia em demasia o desenvolvimento de algumas poucas habilidades de pensamento, dando ênfase especialmente ao domínio da informação e deixando de lado a de pensar de forma criativa e inovadora (PREDEBON, 200I).

A interpretação do texto dos autores (TIDD; BESSANT; PAVITT, 2008) pressupõe que inovação seja um processo com base em conhecimento científico e tecnológico ou empírico que contém três elementos básicos, conforme apresentado na Figura I.

Figura I Elementos do processo de Inovação

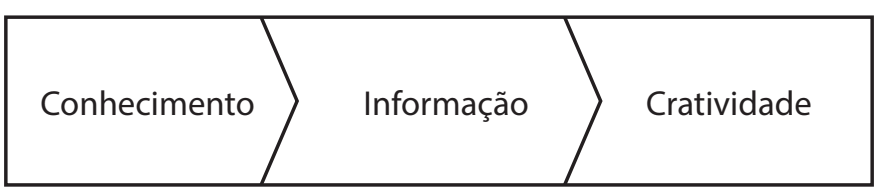

Fonte: Adaptado a partir de Tidd, Bessant e Pavitt, 2008.

Esse modelo pode ser entendido como os elementos do processo de inovação. Primeiro se tem o conhecimento como início do processo, o qual deve tornar-se uma informação a respeito do que se pretende e, por último, a criatividade, que permite o processo de inovação. 


\section{GESTÃO DA INOVAÇÃO}

A inovação produz valor social aos povos, regiões e mercados, e riqueza às indústrias. Contudo, embora altamente dependente de novos conhecimentos técnicos e tecnológicos, a inovação é também um processo estruturado e, em Administração, todo processo deve ser passível de controle. Tal controle refere-se à aplicação dos fundamentos da administração - planejar, organizar, dirigir e controlar - na forma de ciclo de vida do processo de inovação.

O processo de administração das inovações toma o significado de gestão da inovação (TIDD; BESSANT; PAVITT, 2008), e que deve ser um processo contínuo de incentivo à criatividade, ao compartilhamento de ideias e conhecimentos (LAMENZA; BRESCIANI, 2008), uma vez que o resultado final do desenvolvimento de novos produtos ou serviços possui sentido econômico (STAL, 2007), especialmente, quando se associa o papel do empreendedorismo "como um conceito amplo que tem um papel central na economia de mercado. Crescimento econômico, tecnologia moderna e inovação são três variáveis relacionadas ao empreendedorismo" (HUSSAIN et al., 20II, p. 46). Os autores ainda destacam que o empreendedorismo é a Magnífica capacidade e a vontade de um empreendedor, dentro e fora das organizações existentes para identificar e criar novas oportunidades econômicas como novos produtos, novos métodos de produção e nova combinação de produto-mercado e apresentar suas ideias inovadoras para o mercado (HUSSAIN et al., 20II, p. 47).

Essa força está presente no empreendedor e, mais de forma mais restrita ao produto, no inventor. Uma nova máquina, um novo processo de se fazer algo diferente, uma nova técnica para utilizar um equipamento só passará do estágio de invenção para inovação quando puder ser utilizada para fins de geração de lucro. Sem lucro, não há inovação (CAMERINI, 20II). A distinta criação de produto, processo ou técnica, por si só, é uma invenção.

Uma invenção é uma ideia, um esboço ou um modelo para um novo ou aprimorado instrumento, produto, processo ou sistema. Uma inovação no sentido econômico é acompanhada pela primeira transação comercial envolvendo o novo instrumento, produto, processo ou sistema. São importantes não somente para sustentar o crescimento econômico, "mas 
também para, no sentido mais fundamental, permitir às pessoas fazerem coisas que nunca haviam sido feitas anteriormente" (FREEMAN; SOETE, 2008, p. 19). Até transformarem-se em produtos e serviços comercializáveis, as invenções são de certa forma, irrelevantes economicamente, ainda que potencialmente revolucionárias.

Como um fato potencialmente gerador de novos mercados e indústrias, a inovação refere-se desde a introdução, com êxito, no mercado, de produtos, serviços, processos, métodos e sistemas que não existiam anteriormente ou que contenham alguma característica nova e diferente do padrão em vigor. A inovação é, também, a solução inédita de um problema tecnológico, em um processo que inclui: a pesquisa básica, a pesquisa aplicada, o desenvolvimento experimental, a engenharia não rotineira, o protótipo e a comercialização pioneira, até a introdução do novo produto no mercado em escala comercial, tendo, em geral, fortes repercussões socioeconômicas (LONGO, 2004). A Figura 2 apresenta o fluxo da inovação aplicado à geração de novos produtos, impulsionados pelos avanços da Ciência ou por demandas de mercado. 
Figura 2 Pesquisa \& Desenvolvimento

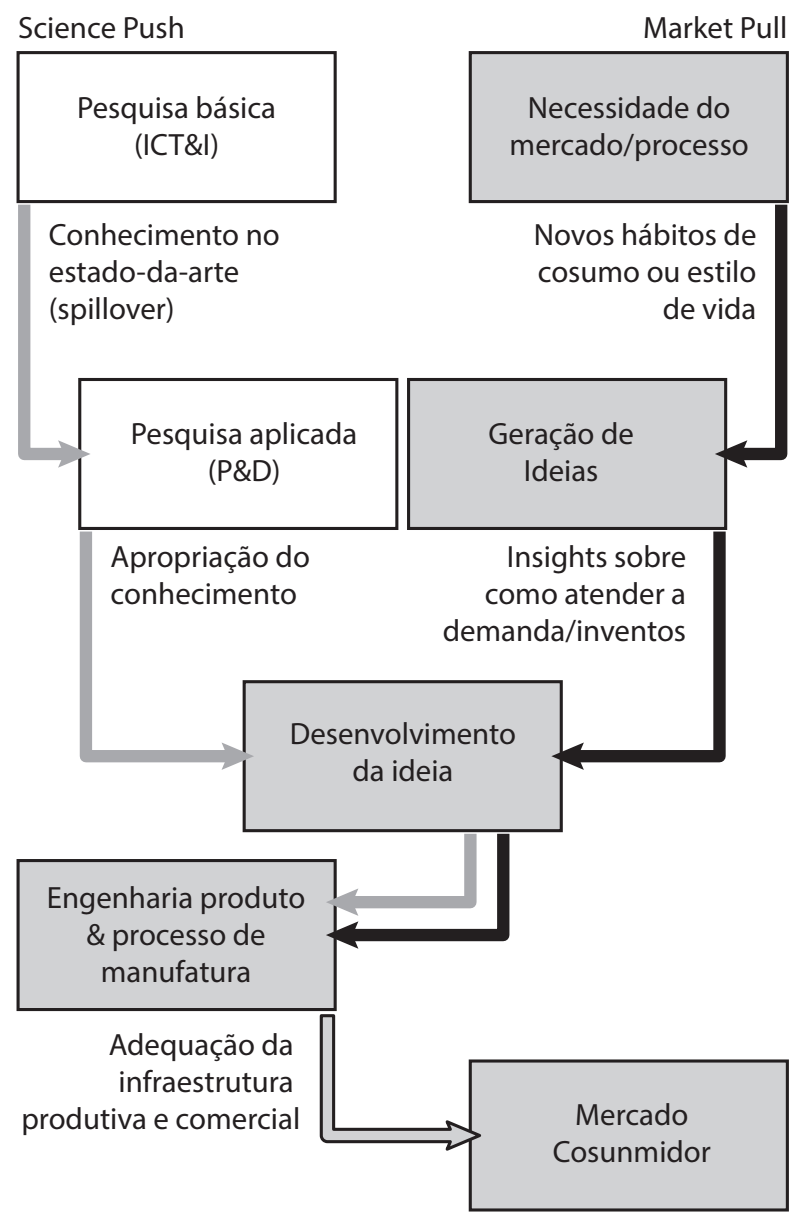

Fonte: Adaptado de Gavioli (2010).

No caso da Inovação em Serviços, pela diversidade de oferta no setor, o Manual de Oslo (2005, p. 30) reconhece a dificuldade de estabelecer um conceito amplo, como é o caso da inovação tecnológica em produtos e serviços (TPP). Uma aproximação teórica do modelo descrito por Antunes Júnior, Leis e Marcantonio (2012) está apresentada na Figura 3. 
Figura 3 Ciclo de Inovação em Serviços: uma aproximação teórica

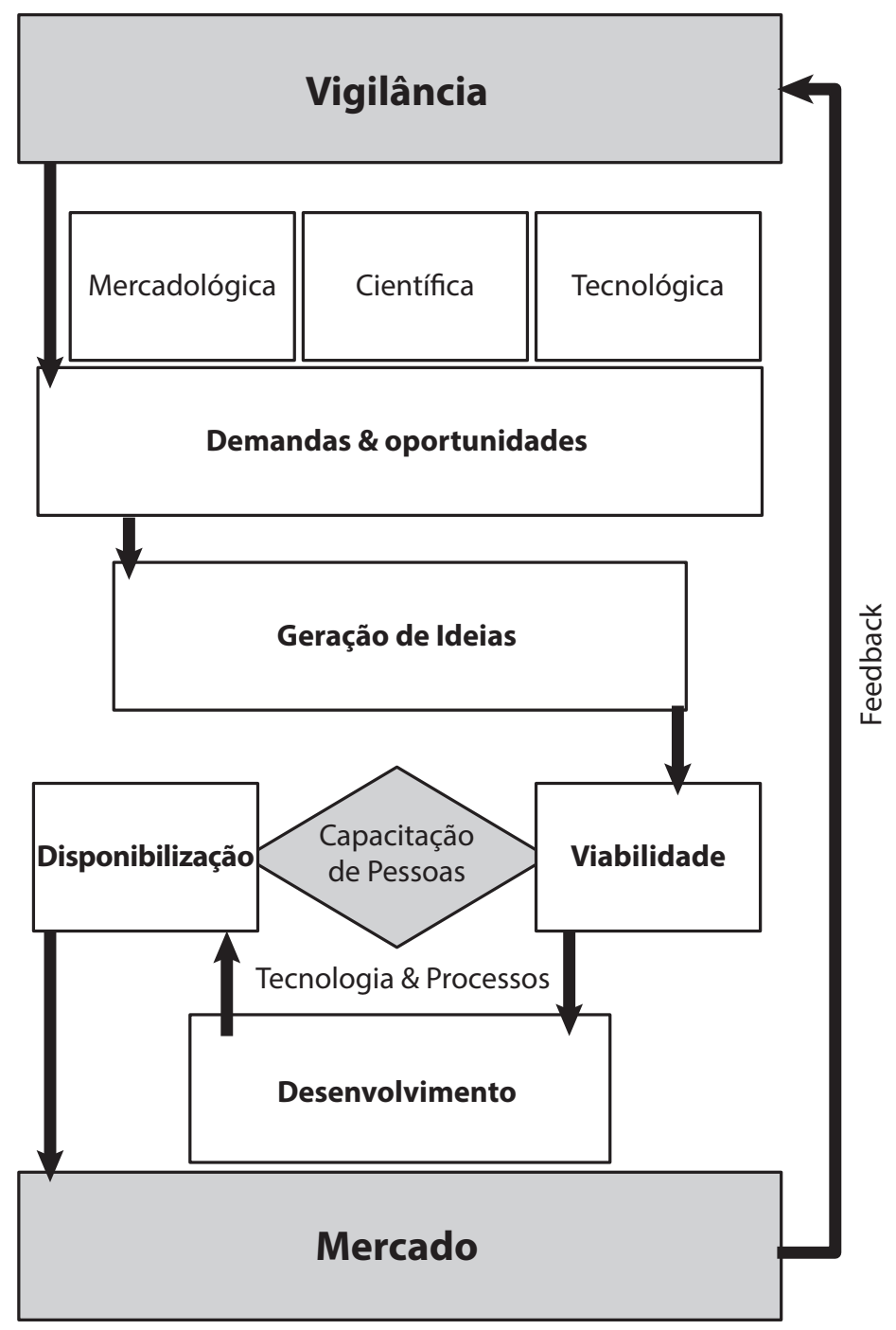

Fonte: Adaptado de Antunes Júnior, Leis e Marcantonio (2012). 
O que se observa nos ciclos de inovação apresentados anteriormente e que ressalta a necessidade de inserir a inovação no contexto gerencial mais amplo em razão das decorrências do novo produto para as funções organizacionais.

Além disso, em se tratando de inovação orientada para o mercado (market pull) é preciso orientar o processo que a desenvolva, no formato de um business case, ou seja, uma análise gerencial envolvendo problema, objetivo, necessidades e expectativas, hipótese de solução, abordagem recomendada, riscos a serem gerenciados e valor agregado com a solução proposta (McGHEE; McALINEY, 2007, p 32). Isto é, organizar o processo de inovação em serviços com base nas premissas do papel gerencial, i.e., planejar a ação frente aos objetivos, liderar pessoas, organizar recursos e controlar resultados.

\section{INOVAÇÃO TECNOLÓGICA E INOVAÇÃO ORGANIZACIONAL}

No contexto empresarial, inovação tecnológica refere-se tanto às inovações organizacionais quanto às tecnológicas. Inovação organizacional é a introdução de novidades que modificam os processos administrativos, tais como a maneira como as decisões são tomadas, a alocação de recursos, as atribuições de responsabilidades, os relacionamentos interpessoais, os sistemas de recompensas e punições e outros elementos relacionados com os processos administrativos. Inovação tecnológica é a introdução de novidades tecnológicas que se apresentam na forma de produtos e processos, novos ou modificados (BARBIERI; ÁLVARES, 2002). "Existem vários tipos de inovação, mas a que mais se destaca pelas mudanças que promove é a tecnológica, ou seja, aquele tipo de inovação cuja matéria-prima é a tecnologia” (CAMPANÁRIO et al., 2005, p. 63).

Para Tigre (2006), a inovação tecnológica é essencial para a produtividade e competitividade das organizações e para o desenvolvimento econômico de regiões e países. A informação e o conhecimento são determinantes para o desenvolvimento qualitativo da produção e dos processos de agregação de valor à produção.

As inovações, de acordo com diversas fontes, (KNIGHT, I967; MANUAL DE OSLO, 2005; ANDREASSI, 2006; LAMENZA; BRESCIANI, 2008), podem ser classificadas por tipos, tal apresentado no Quadro I. 
Quadro I Síntese das classificações de inovação

\begin{tabular}{|c|c|c|}
\hline Autores & Tipologia da inovação & Breve descrição \\
\hline \multirow[t]{4}{*}{ Knight (1967) } & Produto ou serviço & Introdução de novos produtos ou serviços. \\
\hline & Processo de produção & $\begin{array}{l}\text { Introdução de novos elementos nas tarefas da } \\
\text { organização. }\end{array}$ \\
\hline & Estrutura organizacional & Mudanças nas relações de autoridade. \\
\hline & Pessoas & $\begin{array}{l}\text { Inovações que podem mudar o comportamento } \\
\text { das pessoas. }\end{array}$ \\
\hline \multirow[t]{4}{*}{$\begin{array}{l}\text { Manual de Oslo } \\
(2005)\end{array}$} & Produtos & $\begin{array}{l}\text { Introdução de um bem ou serviço novo ou } \\
\text { significativamente melhorado. }\end{array}$ \\
\hline & Processo & $\begin{array}{l}\text { Implantação de métodos de produção } \\
\text { ou distribuição de produtos novos ou } \\
\text { significativamente melhorados. }\end{array}$ \\
\hline & Organizacional & $\begin{array}{l}\text { Implantação de um novo método organizacional } \\
\text { nas práticas de negócios da empresa. }\end{array}$ \\
\hline & Marketing & $\begin{array}{l}\text { Implantação de um novo método de marketing, } \\
\text { envolvendo mudanças significativas na concepção } \\
\text { do produto. }\end{array}$ \\
\hline \multirow[t]{4}{*}{ Andreassi (2006) } & Interna às empresas & $\begin{array}{l}\text { Pesquisa e Desenvolvimento (P\&D), Engenharias, } \\
\text { Marketing e sistemas de relacionamento. }\end{array}$ \\
\hline & Relacionadas à operação & $\begin{array}{l}\text { Fornecedores, clientes e os concorrentes da } \\
\text { empresa. }\end{array}$ \\
\hline & Domínio público & $\begin{array}{l}\text { Artigos publicados em periódicos científicos, teses, } \\
\text { feiras e exposições e congressos científicos. }\end{array}$ \\
\hline & Variadas & $\begin{array}{l}\text { Quando as transações com as empresas são } \\
\text { essencialmente de informações e conhecimento, } \\
\text { sendo públicas e outras empresas privadas. }\end{array}$ \\
\hline \multirow{3}{*}{$\begin{array}{l}\text { Freeman e Soete } \\
\text { (2008); Perez } \\
\text { (2011) }\end{array}$} & Incremental & $\begin{array}{l}\text { Traz pouca alteração na estrutura industrial ou } \\
\text { mudanças mínimas em produtos. }\end{array}$ \\
\hline & Radical & $\begin{array}{l}\text { Introdução de um novo produto com diferenças } \\
\text { muito significativas em relação ao anterior. }\end{array}$ \\
\hline & Revolucionária & $\begin{array}{l}\text { As mudanças são transversais em relação aos } \\
\text { sistemas econômico e social, tornando-se um novo } \\
\text { paradigma tecnoeconômico. }\end{array}$ \\
\hline
\end{tabular}

A inovação é o instrumento específico dos empreendedores, o meio pelo qual eles exploram a mudança como uma oportunidade para um negócio diferente ou um serviço diferente. Os empreendedores precisam buscar, com propósito deliberado, as fontes de inovação, as mudanças e seus 
sintomas que indicam oportunidades para que uma inovação tenha êxito. Os empreendedores por sua vez precisam conhecer e colocar em prática os princípios da inovação bem sucedida (DRUCKER, 2008).

O fenômeno da substituição tecnológica de produtos também está relacionado à inovação, não necessariamente pela evolução de um determinado produto e sim pela criação de um produto novo com proposta de utilização nova e com retornos financeiros. Este tipo de inovação acaba por mudar os hábitos do usuário final, que vê no novo produto vantagem significativa, não só em preço, mas, em usabilidade e satisfação das suas necessidades.

Para Christensen (200I), o conceito de inovação de ruptura é o que leva empresas a um alto grau de sucesso pelo aproveitamento de uma oportunidade ímpar, mas que não é, necessariamente, uma inovação tecnológica radical. O autor chama de tecnologia incremental a que dá suporte à melhoria do desempenho de produtos estabelecidos. Ocasionalmente, ocorrem as tecnologias de ruptura, que trazem ao mercado uma proposição de valor muito diferente daquela até então disponível. Produtos baseados nessas tecnologias são geralmente baratos, simples, menores e de uso conveniente.

Christensen (200I) considera o mercado como o mais importante propulsor das inovações e muitas vezes não é uma nova e sofisticada tecnologia que vai assegurar a vantagem competitiva. $\mathrm{O}$ autor descreve vários casos de empresas líderes em setores industriais, com base em tecnologias sustentadoras (ou sustentáveis), que se viram ameaçadas por novos entrantes que ofereciam produtos com tecnologia similar, porém com formas ou desempenho mais atraentes, mais convenientes, de custo menor e que atendiam a clientes que os concorrentes não se interessavam em atender.

\section{ESTRATÉGIAS DE INOVAÇÃO EM RELAÇÃO À INOVAÇÃO TECNOLÓGICA}

São seis os tipos de estratégias adotadas em relação à inovação tecnológica: ofensiva, defensiva, imitativa, dependente, oportunista e tradicional 
(FREEMAN, I974). O Quadro 2 apresenta um resumo das estratégias utilizadas.

Quadro 2 Estratégias tecnológicas utilizadas pelas empresas em relação à inovação

\begin{tabular}{|ll|}
\hline Estratégias & Contextualização \\
\hline Ofensiva & $\begin{array}{l}\text { Adotada por uma empresa que visa à liderança, diante de seus concorrentes, no } \\
\text { mercado e na tecnologia. }\end{array}$ \\
\hline Defensiva & Querem correr menos riscos, mas não querem ficar muito atrás do mercado. \\
\hline Imitativa & $\begin{array}{l}\text { Firmas que adotam essa estratégia reagem às inovações, mas sua posição de } \\
\text { mercado é garantida por meio de cópias. }\end{array}$ \\
\hline Dependente & $\begin{array}{l}\text { Estratégia dependente é típica de empresas que estão institucional ou } \\
\text { economicamente sujeitas a outras, como as subsidiárias de multinacionais ou } \\
\text { fornecedoras de outras firmas, especialmente no setor de autopeças. }\end{array}$ \\
\hline Oportunista & $\begin{array}{l}\text { A empresa explora nichos de mercado. } \\
\text { Tradicional }\end{array}$ \\
\hline
\end{tabular}

Fonte: Adaptado de Freeman (1974).

A estratégia ofensiva é adotada por empresas que visam à liderança, diante de seus concorrentes, no mercado e na tecnologia. As características predominantes são a excelência técnica dos produtos e agressividade mercadológica. Outras características que devem estar presentes são a exploração precoce de novas descobertas científicas e a manutenção de fortes vínculos com universidades e institutos de Pesquisa \& Desenvolvimento (P\&D). Apenas um pequeno grupo de empresas adota esta estratégia de inovação ofensiva no início até lançar um novo produto, e depois passam a colher os frutos daquela inovação bem-sucedida. Tornam-se defensivas, o que não significa abdicar de $\mathrm{P} \& \mathrm{D}$, mas podem enxergar vantagens em serem seguidoras do líder, adaptando o produto às necessidades dos clientes, aprendendo com a experiência do líder ofensivo, sem repetir suas eventuais falhas, e obtendo diferenciação (PORTER, I992). 
Empresas que adotam a estratégia imitativa reagem às inovações, mas sua posição de mercado é garantida por meio de cópias, com algumas modificações, de projetos dos concorrentes e, com frequência, por alguma proteção ou reserva de mercado. Nesses casos, as empresas preferem licenciar tecnologias estrangeiras, adaptando-as, por meio de design e engenharia de processo ou produto, ao mercado em que atuam (TEIXEIRA, 1983). Essa também é uma estratégia de segmento tecnológico, mas nesse caso a busca é pela vantagem de custo, não pela diferenciação, evitando-se os custos de Pesquisa e Desenvolvimento (PORTER, I992).

A estratégia dependente é típica de empresas que estão sujeitas a outras, como as subsidiárias de multinacionais ou fornecedoras de outras firmas. Nesses casos, as inovações são especificamente demandadas pelas matrizes ou empresas compradoras dos seus produtos.

Na estratégia oportunista, a empresa explora nichos de mercado. Depende fortemente da sensibilidade de um empreendedor para identificar um nicho inexplorado, uma nova oportunidade de mercado, que não exija quase investimentos em P\&D.

A estratégia tradicional prescinde das inovações tecnológicas e está basicamente em setores que não demandam mudanças. Em geral, são empresas que atuam em setores que atendem a necessidades básicas do mercado e não exigem capacitação técnico-científica.

\section{SISTEMAS DE INOVAÇÕES, NACIONAIS, REGIONAIS E LOCAIS}

Um Sistema Nacional de Inovação (SNI) pode ser definido como uma rede de instituições públicas e privadas que interagem para promover o desenvolvimento científico e tecnológico de um país, conforme pode ser visto no Quadro 3. Incluem-se universidades, escolas técnicas, institutos de pesquisa, agências governamentais de fomento, empresas de consultoria, empresas industriais, associações empresariais e agências reguladoras, em um esforço de geração, importação, modificação, adaptação e difusão de inovações (NELSON, I993). 
Quadro 3 Sistemas de inovações

\begin{tabular}{|ll|}
\hline $\begin{array}{l}\text { Sistemas de } \\
\text { Inovação }\end{array}$ & Contextualização \\
\hline Nacional & $\begin{array}{l}\text { Rede de instituições públicas e privadas que interagem para promover o } \\
\text { desenvolvimento científico e tecnológico de um país (NELSON, 1993). }\end{array}$ \\
\hline Regional & $\begin{array}{l}\text { Originou-se a partir dos estudos sobre Sistemas Nacionais de Inovação e sobre } \\
\text { os aspectos ligados ao desenvolvimento regional (COOKE, 2002). }\end{array}$ \\
\hline Local & $\begin{array}{l}\text { São arranjos produtivos em que há interdependência, articulação e vínculos } \\
\text { consistentes, resultando em interação, cooperação e aprendizagem com } \\
\text { potencial para incentivar o aumento da capacidade de inovação endógena, dá } \\
\text { competitividade e do desenvolvimento local (LASTRES; CASSIOLATO 2003). }\end{array}$ \\
\hline
\end{tabular}

É importante destacar que um sistema de inovação é, sobretudo, um sistema de relacionamento entre atores, em um dado recorte territorial. Uma das primeiras tentativas de representação esquemática dos SNI’s foi atribuída por Sábato e Botana, no fim da década de 1970. Nesse modelo, a triangulação se dava em torno das relações entre Governo, Estrutura Tecno-Científica e Estrutura Produtiva, e ficou conhecido como "Triângulo de Sábato" (SÁBATO; BOTANA, 1970, p. 7).

Em meados dos anos 1990, surgiu a metáfora da Hélice Tripla, apresentada na Figura 4, a qual ilustra a criação de empreendimentos, dentro e fora da universidade, que envolvem cooperação entre universidade, indústria e governo.

Figura 4 Hélice Tríplice

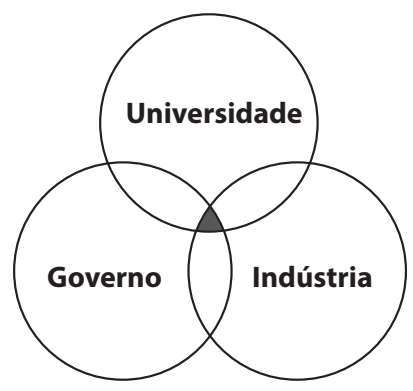

Fonte: Adaptado de Leydesdorff e Etzkowitz (1998). 
A Hélice Tríplice é um modelo espiral de inovação que leva em consideração as múltiplas relações recíprocas em diferentes estágios do processo de geração e disseminação do conhecimento. Cada hélice é uma esfera institucional independente, mas trabalha em cooperação e interdependência com as demais esferas, por meio de fluxos de conhecimento entre elas. Além das conexões entre as esferas institucionais, cada uma assume, cada vez mais, o papel das outras - as universidades assumem postura empresarial, licenciando patentes e criando empresas de base tecnológica, enquanto firmas desenvolvem uma dimensão acadêmica, compartilhando conhecimentos entre elas e treinando seus funcionários em níveis cada vez mais elevados de qualificação (LEYDESDORFF; ETZKOWITZ, I998).

O processo de mudança tecnológica em países em desenvolvimento consiste na aquisição e no melhoramento de capacidade tecnológica, não em inovações na fronteira do conhecimento. Essencialmente, aprendese a usar e a aprimorar tecnologias existentes nos países desenvolvidos. Essa não é uma tarefa simples e sem custos, e o sucesso industrial vai depender da gestão desse processo: como todos os países têm acesso a esses conhecimentos técnicos, um determinante crítico do desempenho empresarial é o nível distinto de aprendizado tecnológico por parte dos diferentes países (LALL, 2000).

O aprendizado ativo é condição necessária, mas não suficiente, para atingir o desenvolvimento. Países desenvolvidos são competitivos porque possuem forte atividade tecnológica. Logo, são necessários esforços tecnológicos domésticos para que os países em desenvolvimento se tornem independentes e competitivos. Nesse estágio, as políticas públicas não precisam privilegiar exclusivamente a inovação, mas é importante o aperfeiçoamento da estrutura técnica de educação que possibilite a formação de mão-de-obra qualificada e a capacitação em pesquisa e desenvolvimento (SBRAGIA; STAL, 2004).

A rigor, e em todos os países, mesmo nos mais desenvolvidos, o governo incentiva as atividades de inovação nas empresas. Seja com isenção ou redução de impostos, financiamentos com juros mais baixos, subvenção econômica e bolsas de pesquisa são alguns dos mecanismos utilizados. Isso 
porque a inovação traz grandes riscos, tanto tecnológicos como comerciais, mas seus benefícios são consideráveis e favorecem toda a sociedade (SBRAGIA; STAL, 2004).

Viotti (2002) afirma que países retardatários serão capazes de, no máximo, fazer inovações incrementais. Considera que tais países não possuem Sistemas Nacionais de Inovação, mas Sistemas Nacionais de Aprendizado Tecnológico. Para o autor, o aprendizado tecnológico é o processo de mudança técnica dada pela absorção de técnicas existentes, isto é, por absorção (difusão) de inovações produzidas em outros países e por introdução de melhorias a partir das técnicas adquiridas (inovação incremental). A Figura 5 apresenta o fluxo debatido por Viotti (2002).

Figura 5 Sistemas nacionais de mudança técnica

Sistemas nacionais de inovação (Países desenvolvidos)

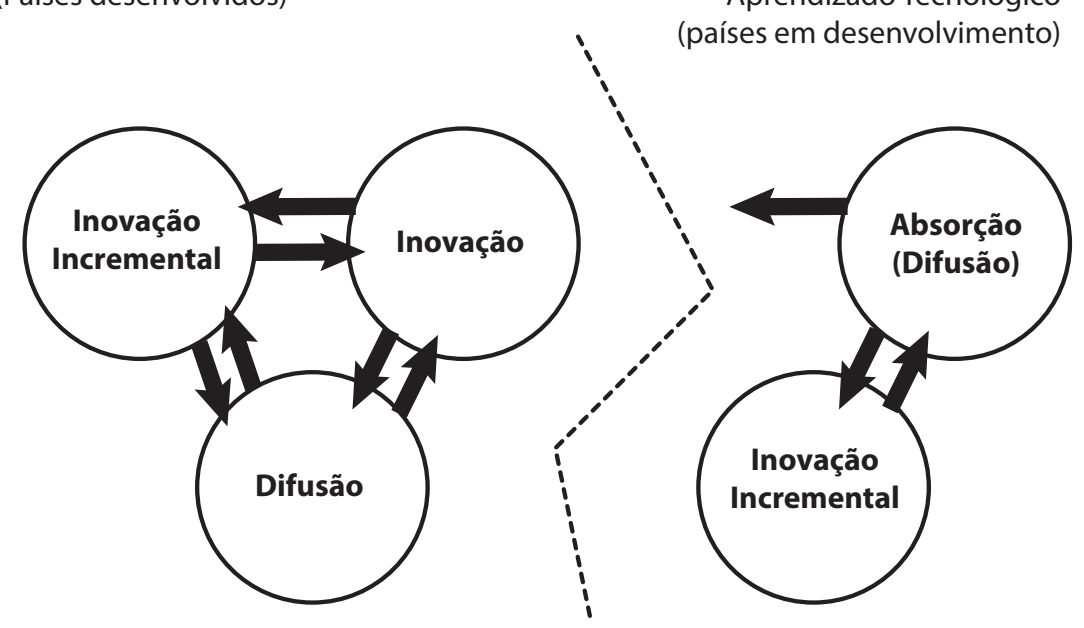

Fonte: Viotti (2002, p. 659).

Assim, um país que pretenda ser economicamente desenvolvido deve criar espaços de interação entre Governo, Ciência e Tecnologia e Empreendedores de Empresas de Base Tecnológica, além de provocar o interesse das indústrias criativas, seja por atratividade da infraestrutura, perpetrando maior visibilidade 
dos fatores da localidade, oferta de mão de obra qualificada, existência de cadeias produtivas e mercado de consumo, além de fonte de insumos, seja pelo fomento direto ao desenvolvimento tecnológico, como ocorre atualmente com os fundos setoriais, fundos constitucionais e agências de financiamento. Como a FINEP - Financiadora de Estudos e Pesquisas, além das fontes de fomento estatais. Nesse caso, as universidades podem oferecer parcerias efetivas.

Uma questão, porém, deve ser revisitada, que é a preparação do cidadão para um novo cenário econômico, de base industrial e tecnológica. Bem como, dos gestores desse novo tipo de empreendimento que deve fazer valer o investimento público recebido, na forma de abertura de postos de trabalho de alta qualidade. Outra questão que surge refere-se ao status de uma população ou grupo social. É fato que várias medidas de desenvolvimento de uma nação podem ser associadas aos indicadores relacionados à inovação.

Santos (20I4) defende a urgência de uma profunda revisão no atual modelo de ensino-aprendizagem, valorizando a qualidade do ensino, a educação e cultura, a despeito do modelo focado na aprovação automática, embora eivado de boas intenções de inclusão social, ele "dificulta o aprendizado e o controle da disciplina” (MALHEIRO, 2005, p. 93).

Em palestra dirigida aos alunos de Administração, do Centro Universitário Adventista de São Paulo - UNASP, no Dia do Administrador, Santos (20I4) destacou que:

A Educação no Brasil tem atingido graus de ineficiência alarmantes. Mas, ainda é possível piorar bastante esse quadro: no grupo alfabetizado, apurou-se que $27 \%$ são analfabetos funcionais, ou seja, não conseguem interpretar textos, ler documentos ou fazer cálculos simples (SANTOS, 20I4, s/p.). Os dados são do Instituto Paulo Montenegro e relativos à pesquisa INAF 20II e 20I2, e oferecem o seguinte detalhamento: somente $62 \%$ das pessoas com ensino superior e $35 \%$ das pessoas com ensino médio completo são classificadas como plenamente alfabetizadas. No ensino fundamental, $25 \%$ dos indivíduos que completaram o ciclo de ensino estão classificados no nível rudimentar de alfabetização (SANTOS, 20I4, s/p.).

Para efeitos da comparação entre as nações mais ou menos inovadoras, a educação, nos três níveis é avaliada. A Tabela I oferece uma ideia do posicionamento do Brasil frente a outras nações. 
Tabela I Competitividade dos países

\begin{tabular}{|c|c|c|c|c|c|c|c|}
\hline $\begin{array}{l}\text { Competitividade dos } \\
\text { Países }\end{array}$ & USA & Japão & Suécia & $\begin{array}{l}\text { Coréia } \\
\text { do Sul }\end{array}$ & Brasil & Portugal & China \\
\hline $\begin{array}{l}\text { Requisitos Básicos } \\
(30 \%)\end{array}$ & 5.1 & 5.3 & 6.0 & 5.7 & 4.5 & 5.2 & 5.3 \\
\hline Instituições & 4.6 & 5.1 & 5.7 & 4.0 & 3.8 & 4.3 & 6.2 \\
\hline Infraestrutura & 5.8 & 5.9 & 5.7 & 5.9 & 4.0 & 5.5 & 4.5 \\
\hline $\begin{array}{l}\text { Ambiente } \\
\text { macroeconômico }\end{array}$ & 4.0 & 3.7 & 6.2 & 6.2 & 4.7 & 3.9 & 6.2 \\
\hline $\begin{array}{l}\text { Saúde e Educação } \\
\text { Fundamental }\end{array}$ & 6.1 & 6.5 & 6.5 & 6.5 & 5.4 & 6.2 & 6.1 \\
\hline $\begin{array}{l}\text { Eficiência Ampliada } \\
(50 \%)\end{array}$ & 5.6 & 5.3 & 5.3 & 5.0 & 4.5 & 4.5 & 4.6 \\
\hline $\begin{array}{l}\text { Educação Superior e } \\
\text { Treinamento }\end{array}$ & 5.7 & 5.3 & 5.7 & 5.5 & 4.3 & 5.0 & 4.3 \\
\hline $\begin{array}{l}\text { Eficiência de } \\
\text { comercialização de } \\
\text { produtos }\end{array}$ & 4.9 & 5.0 & 5.1 & 4.8 & 4.9 & 4.3 & 4.3 \\
\hline $\begin{array}{l}\text { Eficiência de mercado } \\
\text { de trabalho }\end{array}$ & 5.4 & 4.9 & 4.8 & 4.4 & 4.4 & 3.8 & 4.6 \\
\hline $\begin{array}{l}\text { Financiamento } \\
\text { pata Desenv. Novos } \\
\text { Mercados }\end{array}$ & 5.1 & 4.6 & 5.3 & 4.1 & 4.4 & 3.7 & 4.3 \\
\hline Prontidão Tecnológica & 5.8 & 5.7 & 6.3 & 5.7 & 4.4 & 5.3 & 3.5 \\
\hline Tamanho de Mercado & 6.9 & 6.1 & 4.6 & 5.6 & 5.6 & 4.3 & 6.8 \\
\hline $\begin{array}{l}\text { Inovação e Fatores de } \\
\text { Sofisticação (30\%) }\end{array}$ & 5.4 & 5.7 & 5.6 & 5.0 & 4.0 & 4.0 & 4.0 \\
\hline $\begin{array}{l}\text { Sofisticação dos } \\
\text { Negócios }\end{array}$ & 5.3 & 5.8 & 5.6 & 5.0 & 4.5 & 4.2 & 4.3 \\
\hline Inovação & 5.5 & 5.5 & 5.6 & 4.9 & 3.4 & 3.9 & 3.8 \\
\hline
\end{tabular}

Fonte: World Economic Forum (2012-2013).

O nível de desenvolvimento de inovação em uma população, caracterizada e classificada como país, é descrito no Global Innovation Index (GII), que é uma classificação desenvolvida e publicada em conjunto por duas instituições globais, a Institut Européen d'Administration des Affaires- INSEAD, trabalhando como instituição de ensino e pesquisa e com atuação na Europa, Ásia e América; e a World Intellectual Property Organization (WIPO), uma agência especializada das nações unidas que tem como missão promover o 
desenvolvimento econômico, social e cultural de todos os países membros, por meio de um sistema equilibrado e eficaz de propriedade intelectual internacional.

A WIPO é a agência das Nações Unidas dedicada ao uso de propriedade intelectual (patentes, direitos autorais, marcas, desenhos) como um meio de estimular a inovação e a criatividade. O GII (20I2) traz uma compilação de indicadores de inovação globais, desde 2007. Para Dutta e Caulkin (2007), esse indicador pretende evidenciar quais as nações e regiões que respondem melhor ao desafio da inovação e também aponta para os governantes os aspectos principais que podem ser considerados para a melhoria da questão da inovação.

O GII mostra nossa posição comparada a outros players mundiais e as instituições como Índice Brasil de Inovação (IBI) e Pesquisa de Inovação Tecnológica (PINTEC) mostram a realidade interna da inovação empresarial no Brasil. E essa compreensão é essencial ao futuro administrador. Como um recurso igualmente gerenciável, a relação com uma instituição de pesquisa, não necessariamente um instituto de pesquisa, mas, uma universidade poderá atender as demandas da empresa, o que ainda não se nota na maioria dos casos de parceria empresa-universidade.

Somente $20 \%$ das médias empresas usam leis de incentivo à inovação, simplesmente porque as empresas brasileiras de médio porte desconhecem o que é inovação e a sua importância para competir e crescer no mercado (ARÍCIA, 20I2).

\section{O ENSINO DE INOVAÇÃO NA FORMAÇÃO DO ADMINISTRADOR}

\section{BRASILEIRO}

O ensino de Administração no Brasil passou por dois momentos marcados pelos currículos mínimos aprovados em i966 e I993, culminando com a apresentação da proposta de diretrizes curriculares para os cursos de graduação em Administração, em 1998. Por sua vez, os americanos tiveram os primeiros cursos na área no final do século XIX, com a criação da Wharton School, em I88I. Em I952, ano em que se iniciava o ensino de Administração no Brasil, os EUA já formavam em torno de cinquenta mil bacharéis, quatro mil mestres e cem doutores, em Administração, por ano (CFA, 20I3). 
O ensino de inovação não consta como obrigatório na organização curricular do curso de Bacharelado em Administração, embora, no contexto do que deve ser ensinado neste curso, enfatiza-se a importância do ensino da inovação aos futuros profissionais do curso de Administração, entre outros (PEREIRA et al., 20I2).

Observa-se, no entanto (CNS $\left.\mathrm{N}^{\circ} \mathrm{I}, 2004\right)$, que o uso das "tecnologias inovadoras", como são inseridas neste contexto, não trata especificamente do conceito de inovação; as disciplinas como no item I, Tecnologias da Informação e da Comunicação (TIC), no item II, Sistemas de Informações, no item III, Tecnologias em Métodos Quantitativos, estão incluídas em realidade na área de Tecnologia da Informação.

O IBI é um projeto desenvolvido por pesquisadores do Departamento de Política Científica e Tecnológica (DPCT/IG) da Unicamp, a partir de uma iniciativa da editoria da revista Conhecimento \& Inovação. Desenvolveuse uma metodologia para mensurar inovação empresarial considerando os esforços e os resultados das atividades inovativas. A primeira edição do IBI trouxe um ranking de empresas inovadoras do setor de transformação do país, com base na PINTEC de 2003 (FURTADO; QUADROS, 2006).

Nos resultados das pesquisas da PINTEC, infere-se que o perfil da "capacidade de inovar das empresas brasileiras está mais voltado para a replicação de conhecimento e inovações incrementais do que a busca de desenvolvimento de inovações radicais e estratégicas" (SANTOS; BASSO; KIMURA, 20I2, p. I2I). Estes estudos e indicadores mostram parte do que poderia se ensinar no Brasil sobre a inovação e, especificamente ao Administrador, a sua importância no modelo de negócios e na configuração do desenho dos processos organizacionais. 


\section{CONTRIBUIÇÕES TEÓRICAS PARA A FORMAÇÃO DO} ADMINISTRADOR

Ensinar o administrador da maneira convencional, com teorias e reflexão sobre o que foi transmitido em sala de aula, trata apenas de um aspecto do ensino. A reflexão leva à competência, em contraposição à prática, que leva à habilidade. A prática realmente leva o aluno a algo mais utilizável no mundo real, porém, o que se aprende na prática precisa estar atrelado a um ensino de qualidade. Mesmo a mais prática das aulas exigirá alguma pesquisa em relação ao assunto ensinado. Assim, competências e habilidades tornam-se paralelos complementares e não sequências didáticas saudáveis na preparação do aluno.

Assim, pode-se entender como um produto de mercado aquele curso em que o aluno possa compor a sua matriz curricular, observando os pré-requisitos para o tipo de curso que pode ser oferecido. Certamente a proposta desse tipo de educação superior e customizada é muito mais dispendiosa. Trata-se muito mais do perfil do aprendizado do aluno do que da capacidade de aprender, pois entrega um valor adicional que ele está disposto a pagar.

Outra grande oportunidade de não consumo é representada pelos alunos que precisam recuperar créditos. "Existe um grande bloco neste grupo, pois os problemas de recuperação de créditos constituem uma espécie de praga que afeta os estudantes, desde o meio rural até os de inúmeros distritos escolares urbanos" (CHRISTENSEN, 20I2, p. 74). Pelas mais variadas razões, nem sempre existe uma escola auxiliar disponível para os alunos com dependência em determinadas matérias.

Trata-se da formação de um administrador, com os princípios de inovação, contextualizando seus novos conhecimentos com a questão da regionalidade, que por sua vez pode-se influenciar no modo como o novo administrador entenderá a comunidade. 


\section{METODOLOGIA}

A pesquisa classifica-se como exploratória, haja vista que se pretendeu ampliar o conhecimento acerca do que está sendo informado nos websites das IES sobre o ensino de inovação nos cursos brasileiros de Administração. Utilizou-se, neste trabalho, o método de pesquisa documental, entendido como o mais apropriado para que se pudesse detectar como os próprios gestores de cursos divulgam o que se propõem a ensinar.

\section{POPULAÇÃO E AMOSTRA}

A pesquisa de campo teve como ponto de partida conhecer quantas e quais são as IES brasileiras e, destas, quantas e quais oferecem curso de bacharelado em Administração. Por meio de consulta à base de dados do e-MEC, foram identificados 2.689 cursos de bacharelado em Administração no Brasil.

Dentre esses 2.689 cursos, 387 (I4,4\%) continham disciplinas com o termo "inova” na nomenclatura da disciplina, porém sem indicativos sobre publicação nos seus respectivos websites. Para estes registros, procedeu-se à consulta junto aos websites para obtenção das matrizes curriculares que contivessem ementários e bibliografias.

\section{COLETA DE DADOS}

A coleta dos dados foi realizada com base inicial no download dos dados do website do Ministério da Educação, e-MEC, no seguinte endereço: <http://emec.mec.gov.br/>, utilizando-se a opção "Consulta Avançada" e "Cursos", sem informar nenhum parâmetro de pesquisa, escolheu-se a opção "Instituição de Ensino Superior”. Tomou-se o cuidado na verificação dos dados obtidos neste arquivo de dados do e-MEC (20I3), por meio de um processo de envio de mala-direta por e-mail, para as IES que não apresentaram conteúdos nos seus websites, quanto à existência das matrizes curriculares para os cursos de Administração identificados por este mesmo arquivo de dados. Para este trabalho de pesquisa, foram identificados e relacionados todos os responsáveis pelas IES de acordo com o informado 
no próprio formulário do website do e-MEC (2013) que apresenta a janela de consulta com o endereço de e-mail utilizado nesta pesquisa.

A pesquisa com as IES, que não publicam em websites, decorreu em duas etapas, sendo a primeira entre 26/05/2013 e or/07/2013. Solicitou-se aos responsáveis descritos no website do e-MEC a participação na pesquisa. Nesta pesquisa uma carta com o código de retorno da IES e Curso foi incluída e solicitada como "encaminhamento", à resposta do responsável, para que o método da pesquisa documental permanecesse íntegro.

Foram enviados 83I e-mails aos professores responsáveis pelos (2.302) cursos de bacharelado em Administração. Foram obtidas, I4 respostas à pesquisa, o que equivale a I,68\% dos e-mails enviados. Após a leitura e interpretação, estes dados foram incorporados ao banco de dados.

No website do IBGE (20I3), foram coletados os indicadores de população dos estados de acordo com o publicado na página “@estados”. Do total de habitantes foram considerados aqueles que frequentaram cursos de graduação em 2010 e o PIB per capita IBGE (20I2).

Os dados de cada unidade da federação, por região, são apresentados na página síntese do estado. O número de habitantes que frequentou nível superior naquele ano do censo é apresentado na página do "Censo Demográfico 20I0: Educação - Amostra” do respectivo estado. O PIB foi buscado na tabela "Produto Interno Bruto, população residente e Produto Interno Bruto per capita", de acordo com o guia de Contas Regionais do Brasil 2010 (IBGE, 20I2, p. I8). Os dados compilados entre as linhas das regiões são subtotais dos estados que compõem a região. O total é a somatória de todas as regiões do Brasil. 


\section{ANÁLISE DE DADOS}

Um novo filtro de dados foi aplicado para descobrir os cursos inseridos na área de bacharelado em Administração. Assim, apenas cursos com conteúdo contendo "adm" no banco de dados foram selecionados. Desta pesquisa, resultaram 2.689 cursos válidos.

O Gráfico I apresenta a classificação e a seleção do universo pesquisado, por região do país. Os cilindros de cor azul representam a quantidade de cursos encontrados durante a pesquisa e o topo em vermelho representam os cursos efetivamente selecionados.

Gráfico I Seleção das IES para pesquisa

\section{$\square$ Encontradas $\square$ Selecionadas}

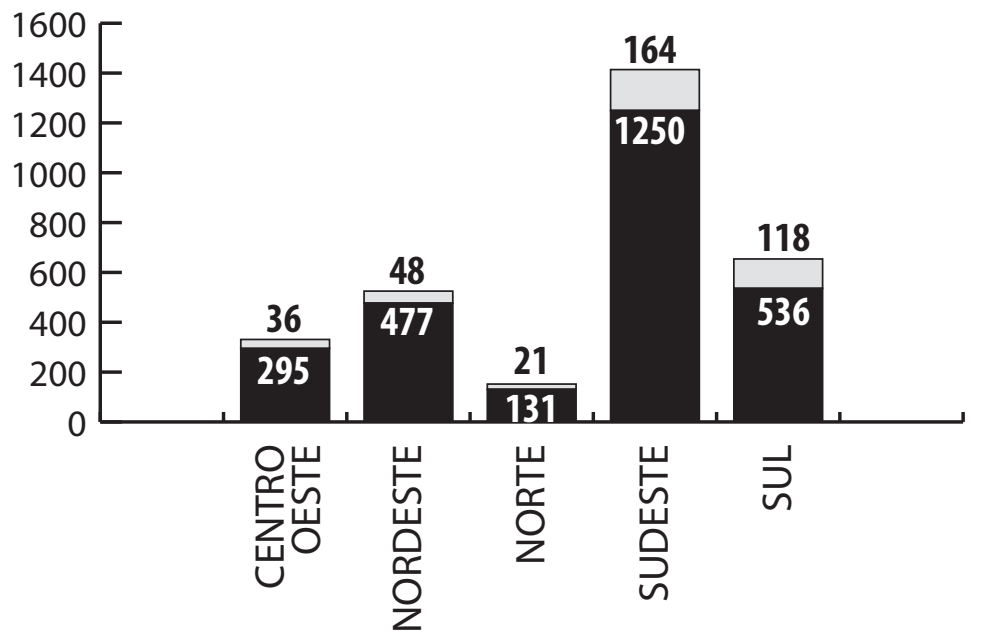

Verificou-se que a região do Brasil com maior quantidade de cursos selecionados proporcionalmente é a sudeste, com 42,4\%, seguida da região sul, com 30,5\%.

Neste sentido, é necessário estar atento ao que se propõe ao ensino e divulgação dos conceitos de inovação. Aqui, corroborando com Stal (2007), 
nota-se que apenas algumas regiões do Brasil concentram o ensino sobre inovação com maior intensidade, embora se deva considerar também que a capacidade de inovar no ensino ainda não representa uma conscientização quanto à abrangência e importância da inovação.

Da mesma forma que os cursos com inovação no título da disciplina, buscou-se saber também nos cursos o ementário e as bibliografias para cada disciplina. Os destaques para publicação nos estados são:

- $\quad$ Rio Grande do Sul com 23;

- São Paulo com 6;

- Distrito Federal com 3;

- Alagoas com 2 e;

- Tocantins com I ementário(s) e bibliografia(s) publicada(s) nos respectivos websites.

Quanto ao cruzamento dos dados econômicos e acadêmicos no Curso de Bacharelado em Administração, primeiramente preparou-se uma tabela igualando na mesma base percentual de grandeza os valores unitários de cada categoria obtidos na pesquisa, para posterior análise dos resultados.

Quanto à publicação dos dados na internet, do total de 2.689 cursos buscados no sistema e-MEC (2013), 2.302 referem-se aos cursos de Bacharelado em Administração (85,6\%) não apresentaram matriz curricular em website. Os demais, 387 (I4,4\%) cursos publicam as disciplinas relacionadas ao termo "inova” somente nas matrizes curriculares. Destes cursos que publicam disciplinas relacionadas ao termo "inova", 4I (I0,6\% - ou I,52\% do total de cursos buscados no e-MEC) publicam as ementas e bibliografias completas.

Das bibliografias relacionadas com inovação mais citadas, em um total de 199 obras, 60 delas (30,15\%) representam as io primeiras referências comumente indicadas.

Ainda com relação ao detalhamento e análise dos ementários, procurouse saber os assuntos mais difundidos nos cursos de Bacharelado em Administração das IES Brasileiras. O Quadro 4 apresenta uma relação dos conhecimentos mais difundidos. 
Quadro 4 Principais assuntos relacionados nos ementários

\begin{tabular}{|c|c|}
\hline Região & Assuntos relacionados nos ementários \\
\hline Norte & $\begin{array}{l}\text { - características das inovações } \\
\text { - conceitos de inovação } \\
\text { - fontes de inovação } \\
\text { - inovação organizacional } \\
\text { - inovação tecnológica }\end{array}$ \\
\hline Nordeste & $\begin{array}{l}\text { - conceitos de inovação } \\
\text { • clima para inovação na empresa } \\
\text { - competitividade empresarial } \\
\text { - inovação organizacional } \\
\text { - inovação tecnológica }\end{array}$ \\
\hline $\begin{array}{l}\text { Centro } \\
\text { Oeste }\end{array}$ & $\begin{array}{l}\text { - convênios internacionais } \\
\text { • criatividade, informação e conhecimento } \\
\text { • inovação organizacional } \\
\text { - inovação tecnológica } \\
\text { - pesquisa industrial }\end{array}$ \\
\hline Sudeste & $\begin{array}{l}\text { - crescimento e competitividade } \\
\text { - economia e inovação } \\
\text { - gestão da inovação } \\
\text { - inovação organizacional } \\
\text { - inovação tecnológica } \\
\text { - TIC's }\end{array}$ \\
\hline Sul & $\begin{array}{l}\text { - gestão da inovação } \\
\text { - indicadores de inovação } \\
\text { • informação, conhecimento e criatividade } \\
\text { - inovação organizacional } \\
\text { - inovação tecnológica } \\
\text { - TIC's }\end{array}$ \\
\hline
\end{tabular}

Por sua vez, os professores participantes da pesquisa são unânimes ao afirmar a necessidade de se dar mais ênfase ao ensino de inovação, haja vista a necessidade a academia acompanhar o acelerado ritmo do mercado, que investe pesadamente em P\&D e cotidianamente inova em produtos, processos e serviços. 


\section{CONSIDERAÇÕES FINAIS}

Foram encontradas 2.636 IES e 2.689 cursos cadastrados no sistema e-MEC, sendo que das IES localizadas, 387 (I4,68\%) apresentam os termos "inova" nas disciplinas divulgadas nos websites das referidas IES, nos cursos de Bacharelado em Administração. Dos cursos cadastrados, 2.302 cursos não estão acessíveis via website ou não se disponibilizam hiperlinks para consultas à matriz curricular do curso de Bacharelado em Administração.

A pesquisa levou em conta os registros do site do e-MEC (20I3) e também se aprofundou nos cursos que apresentaram em suas disciplinas algum termo relacionado com inovação e que não foi encontrada informação nos websites das IES.

Das 2.636 IES pesquisadas, 4I (I,56\%) apresentaram ementários por meio eletrônico, nos quais foi identificado e compilado um conjunto de informações que caracterizam o conteúdo programático que está sendo ensinado em cada região do Brasil.

O Brasil poderá se desenvolver mais e melhor ao mesmo tempo em que se apropria dos avanços da inovação tecnológica, de tal forma que possa romper o paradigma dos países que mais se assemelham com replicadores de inovações. Para isto, é importante um forte esquema de parceria entre empresas e as instituições de ensino que promovam a pesquisa. Porém, poder-se-ia começar este movimento com maior integração entre as informações produzidas pelas IES, como por exemplo, a publicação das matrizes e ementários, pois isto também é uma formalização da transparência necessária para as empresas escolherem seus parceiros na pesquisa da inovação.

Torna-se clara a emergência de informações mais estruturadas nos websites das IES a ponto de permitir que as escolhas dos próprios alunos sejam mais realistas e possam promover uma "evolução do grupo" dos alunos que poderão comparar discutir mais seus objetivos e as prioridades dos seus papéis.

Para o estudo da inovação, GII, PINTEC e IBI são exemplos de indicadores de inovação que devem ser estudados e discutidos com maior ênfase em sala de aula. 
Ao comparar a bibliografia levantada com o resultado da pesquisa e comparando-se à pesquisa ANGRAD (2013), nota-se que não houve aconselhamento específico para o assunto inovação. Os periódicos coincidentes na pesquisa e na publicação da ANGRAD foram a Revista Brasileira de Inovação (RBI), destinada à comunidade científica para divulgação de artigos, com publicação semestral, e a Revista de Administração e Inovação (RAI), destinada à publicação institucional dos grupos de pesquisa da FGV-EAESP, GEMPI/UNICAMP, GEOPI/ UNICAMP, NEI/UNINOVE, PGT/USP, EBAPE/FGV, UNB e NITEC/ UFRGS. As bases de dados indicadas na pesquisa e que também aparecem na pesquisa ANGRAD é a OECD (Organization for Economic Co-operation and Development) estão disponíveis na biblioteca eletrônica Source/OECD, que inclui periódicos, livros, estatísticas e outras coleções publicadas pela OECD. Trata-se de uma coleção multidisciplinar, cobrindo todas as áreas do conhecimento, com ênfase em Economia e Geografia Econômica.

Os websites pesquisados tratam a informação sobre inovação nas disciplinas constantes em suas matrizes curriculares de forma superficial. Foram encontradas situações que não estabelecem ligação entre o informado no título da disciplina, a ementa do curso e a bibliografia, provável justificativa para a escassez de disciplinas com conteúdo ligado à inovação nos cursos superiores pesquisados, pois há pouca ou nenhuma divulgação pública de ementas e bibliografias nestas disciplinas.

Ao se comparar o que se ensina de inovação em Administração com as características das regiões Brasileiras apontadas nos indicadores da população e economia divulgados pelo IBGE, nota-se uma relação direta entre a economia do estado e a quantidade de alunos que frequentam o nível superior. Porém, quando o assunto é inovação em cursos de Bacharelado em Administração, a análise dos números mostra certo alinhamento global com tendência para os estados mais desenvolvidos do Brasil.

Entende-se como limitação desta pesquisa o fato de se ter objetivado investigar o que as IES divulgam ensinar nos cursos de Administração e não o que elas efetivamente ensinam, até porque o tema "inovação" pode ser considerado transversal, pois pode estar sendo ensinado em 
diversas disciplinas, embora não esteja registrado como conteúdo, nome de disciplina ou ainda parte da ementa.

Para pesquisas futuras sugere-se o aprofundamento da investigação, especialmente nos conteúdos das diversas disciplinas ministradas nos cursos de Administração, para que se possa identificar de forma mais específica o que está sendo ensinado dentro de cada disciplina, de forma a evidenciar possíveis lacunas, as quais deverão ser sanadas pelas instituições de ensino. 


\section{REFERÊNCIAS}

AT KEARNEY. Innovation Management: strategies for success and leadership. Chicago: AT Kearney, 2008.

ANDREASSI, T. Inovação e competição. In: SBRAGIA, R. (Coord.). Inovação: Como vencer este desafio empresarial. São Paulo: CLIO, 2006.

ANGRAD - Associação Nacional dos Cursos de Graduação em Administração. Bibliografia básica de referência ANGRAD para os cursos de graduação em administração. Rio de Janeiro: ANGRAD, 2013.

ANTUNES JÚNIOR, J. A. V.; LEIS, R. P.; MARCANTONIO, M. I. P. O polo de inovação tecnológica da região norte do Rio Grande do Sul à luz dos sistemas regionais de inovação: sua evolução, aspectos facilitadores e limitadores. Revista Brasileira de Inovação, v. 11, n. 2, p.435-466, 2012.

ARÍCIA, Martins. Só $20 \%$ das médias empresas usam leis de incentivo à inovação, diz estudo. Jornal o Valor Econômico. São Paulo. 08/06/2012.

BARBIERI, J. C.; ÁLVARES, A. C. T. Meio Inovador Empresarial: Conceitos, Modelos e Casos. Revista IMES Administração, ano XIX, n. 56, p. 34-43, 2002.

BRASIL. Resolução CNE/CES no . 01/2004. Institui as Diretrizes Curriculares Nacionais do Curso de Graduação em Administração, bacharelado, e dá outras providências. Disponível em < http://portal.mec.gov.br/cne/arquivos/pdf/rces01_04. pdf $>$. Acesso em: 17/10/2012.

BRASIL. Resolução CNE/CES no . 04/2005. Institui as Diretrizes Curriculares Nacionais do Curso de Graduação em Administração, bacharelado, e dá outras providências. Disponível em <http://portal.mec.gov.br/cne/arquivos/pdf/rces004_05. pdf $>$. Acesso em: 17/10/2012.

CAMPANÁRIO, M. de A.; MACCARI, E. A.; MARTINS, C. B.; MAFFEI, P. A. de J. Inovação incremental: tecnologia da quarta camada da Fujifilm. Revista Gerenciais, v. 4, n. 1-13, p. 63-70, 2005.

CAMERINI, C. Inovação em pauta. Revista da FIEC, ano 5, Ed. 50, 2011.

CFA. CONSELHO FEDERAL DE ADMINISTRAÇÃO. História da Administração no Brasil. Brasília, DF, 2013. Disponível em <http://www2.cfa.org.br/formacaoprofissional/destaques/ma\%20cfa_cras/administracao-financeira $>$. Acesso em: 31/05/2013.

CHAVES, A. Tecnologia. EDTCH - Education Tecnology, 1979.

CHRISTENSEN, C. M. O Dilema da Inovação. São Paulo: Makron Books, 2001.

CHRISTENSEN, C. M.; HORN, M. B.; JOHNSON, C. W. Inovação na Sala de Aula: como a inovação disruptiva muda a forma de aprender. Porto Alegre: Bookman, 2012. 
DRUCKER, P. The Discipline of Innovation. Harvard Business Review, v. 80, n. 8, p. 95-102, 1998.

Inovação e espírito empreendedor (entrepreneurship) prática e

princípios. São Paulo: Cengage Learning, 2008.

DUTTA, S.; CAULKIN, S. The power of innovation, 2007.

e-MEC. Instituições de Educação Superior e Cursos Cadastrados, 2013.

EUROPEAN UNION FOR REGIONAL POLICY. Creativity and Innovation: driving competitiveness in the Region. Acting Together to Promote Creativity and Innovation Panorama Inforegio, n. 29, p. 18-19, 2009.

ETZKOWITZ, H. Entrepreneurial science: the second academic revolution. In:

Seminar on academy-industry relations and industrial policy: regional, national and international issues. State University of New York, 1993.

FLEURY, A.; FLEURY, M. T. L. Aprendizagem e inovação organizacional: as experiências de Japão, Coréia e Brasil. 2.ed. São Paulo: Atlas, 1997.

FREEMAN, C. The economics of innovation. Middlesex: Penguin Books, 1974.

FREEMAN, C.; SOETE, L. A Economia da Inovação Industrial. Campinas: Unicamp, 2008.

FURTADO, A.; QUADROS, R. Construindo o IBI. Inovação Uniemp, v. 2, n. 3, p. 26-27, 2006.

GAVIOLI, M. de C. Inovação na Indústria de Serviços de Telecomunicações: fatores determinantes e impactos na cadeia de valor. Dissertação (Mestrado Profissional) Escola de Administração de São Paulo, 2010.

GOODWIN, A. L. Perspectives on High Performing Education System in Finland, Hong Kong, China, South Korea and Singapore: what lessons for the U.S.? In: LEE, S. K. et al. (Eds.). Educational Policy Innovations: levelling up and sustaining educational achievement. Springer Educational Innovation Book Series 1, Cap. 11, p. 185-199, 2014.

HUSSAIN, M. F.; AFSAL, A.; ASIF, M.; AHMAD, N.; BILAL, R. M. Impact of Innovation, Technology and Economic Growth on Entrepreneurship. American International Journal of Contemporary Research, v. 1, n. 1, p. 45-51, 2011.

IBGE - Instituto Brasileiro de Geografia e Estatística. Estados@. Rio de Janeiro: [s.n]. Disponível em: <http://www.ibge.gov.br/estadosat/>. Acesso em: 02/06/2013.

IBGE - Instituto Brasileiro de Geografia e Estatística. Contas Nacionais: Contas Regionais do Brasil - 2010. Rio de Janeiro, [s.n], 2012. Disponível em: <ftp://ftp.ibge. gov.br/2010/.pdf>. Acesso em: 02/06/2013.

KNIGHT, K. A descriptive model of the intra-firm innovation process. Journal of Business, v. 40, n. 4, p. 479-496, 1967. 
LALL, S. Technological change and industrialization in the Asian newly industrializing economies: achievements and challenges. In: KIM, L.; NELSON, R. (Eds.). Technology, learning $\&$ innovation: Experiences of newly industrializing economies. Cambridge: Cambridge University, 2000.

LAMENZA, A.; BRESCIANI, L. P. Centralidade da Inovação: Estratégia Competitiva e Política Industrial no Brasil. In: LAMENZA, A. (Org.). Estratégias Empresariais: Pesquisas e casos brasileiros. São Paulo: Saint Paul, p. 65-114, 2008,

LAUDON, K. C.; LAUDON, J. P. Sistemas de Informação Gerenciais. 7.ed. São Paulo: Pearson Prentice Hall, 2007.

LEYDESDORFF, L.; ETZKOWITZ, H. Tripe Helix as a model for innovation studies. Sciend and Public Policy, v. 25, n. 3, p. 195-203, 1998.

LONGO, W. P. Conceitos básicos sobre ciência, tecnologia e inovação. 2.ed. Rio de Janeiro: FINEP, 2004.

LUZ, M. da S.; SANTOS, I. C. Ciência, tecnologia e pesquisa tecnológica: a luta por uma política nacional em C\&T. Revista Produção Online, v.7, n. 1, p.154 - 182, 2007.

MANUAL DE OSLO. Proposta de Diretrizes para Coleta e Interpretação de Dados sobre Inovação Tecnológica. 3.ed. Rio de Janeiro: FINEP, 2005.

MATHEUS, R. F. Rafael Capurro e a filosofia da informação: abordagens, conceitos e metodologias de pesquisa para a Ciência da Informação. Perspect. ciênc. inf., v.10 n.2, p.140-165, 2005.

McGHEE, P.; McAlineY, P. Painless Project Management: a step-by-step guide for planning. Hoboken (NJ): John Wiley \& Sons, Inc. 2007.

NELSON, Richard. R. National innovation systems - A comparative analyses.

Oxford: Oxford University, 1993.

$\mathrm{OH}, \mathrm{J}$. High school diversification against educational equality: a critical analysis of neoliberal education reform in South Korea. Asia Pacific Education Review, v. 12, n. 1, p. 381-392, 2011.

PEREIRA, R. da S.; FRANCO, I. D.; ALMEIDA, L. C. B.; SANTOS, I. C. dos. O Ensino de "Inovação" na Administração, Ciências Contábeis, Turismo e Tecnologia em Gestão: Um Estudo Exploratório em Instituições de Ensino Superior Brasileiras. Revista de Administração e Inovação, v. 9, n. 4, p. 221-244, 2012.

PEREZ, C. Technological Revolutions and techno-economic paradigm. Technology Governance. Norway, 2011.

PINTEC. Pesquisa de inovação tecnológica. Rio de Janeiro: [s.n], 2012.

PORTER, M. Vantagem competitiva. 4.ed. Rio de Janeiro: Campus, 1992.

PREDEBON, J. Criatividade: abrindo o lado inovador da mente: um caminho para o exercício prático dessa potencialidade, esquecida ou reprimida quando deixamos de ser crianças. 3.ed. São Paulo: Atlas, 2001. 
SÁBATO, J.; BOTANA, N. La ciencia y la tecnologia en el desarrollo future de America Latina. Políticas CTI, 1970.

SANTOS, I. C. Educação para a Inovação. Ciclo de Palestras em Comemoração ao Dia do Administrador. Palestra ministrada na UNASP - Centro Universitário Adventista de São Paulo. Itapecerica da Serra/SP, 2014.

SANTOS, I. C.; KUBO, E. K.M.; AMORIM, W. A. C. Formação do cluster tecnológico de São José dos Campos: trajetória e implicações. Revista Metropolitana de Sustentabilidade, v. 3, n. 2, p. 23-46, 2013.

SANTOS, I. C.; LUZ, M. da S. Implantação da Política para take off tecnológico e algumas considerações sobre o desenvolvimento nacional. Revista Brasileira de Gestão e Desenvolvimento Regional, v. 3, número especial, p.115 - 139, 2007.

SANTOS, I. C.; MORAIS, P. R.; FREIRE, J. R. de S.; LUZ, M. da S. Managing Innovation under Constraints: A Glimpse on the Brazilian Conditions for Innovation. International Journal of Advances in Management and Economics, v.2, n. 6, p. 131144, 2013.

SANTOS, D. F. L.; BASSO, L. F. C.; KIMURA, H. A estrutura da capacidade de inovar das empresas brasileiras: Uma proposta de constructo. Revista de Administração e Inovação, v. 9, n. 3, p. 103-128, 2012.

SBRAGIA, R.; STAL, E. A empresa e a inovação tecnológica: motivações parceria e papel do estado. Revista Fórum de Líderes Empresariais. Ano VII, n. 11, 2004.

SCHUMPETER, J. Teoria do desenvolvimento econômico: Uma investigação sobre lucros, capital, crédito, juro e o ciclo econômico. São Paulo: Abril Cultural, 1982.

SIMANTOB, M.; LIPPI, R. Guia Valor Econômico de Inovação nas Empresas. São Paulo: Globo, 2003.

STAL, E. Inovação Tecnológica, Sistemas Nacionais de Inovação e Estímulos Governamentais à Inovação. In MOREIRA, D. A.; QUEIROZ, A. C. S. Inovação Organizacional e Tecnológica. São Paulo: Thomson Learning, Cap. 2, p. 23-53, 2007

TEIXEIRA, D. S. Pesquisa, desenvolvimento experimental e inovação industrial: motivações da empresa privada e incentivos do setor público. In: MARCOVITICH, J. (Coord.). Administração em ciência e tecnologia. São Paulo: Edgard Blucher, Cap. 2, p. 45-91, 1983.

TIDD, J.; BESSANT, J.; PAVITT K. Gestão da Inovação. 3.ed. Porto Alegre: Bookman, 2008.

TIGRE, P. B. Gestão da Inovação. Rio de Janeiro: Elsevier, 2006.

TUMELERO, C. Sobrevivência de empresa de base tecnológica pós-incubadas: estudo da ação empreendedora sobre a mobilização e uso de recursos. Dissertação (Mestrado) - Faculdade de Economia, Contabilidade e Administração - Universidade de São Paulo, 2012. 
WORLD ECONOMIC FORUM. The Global Competitiveness Report 2012-2013, Insight Report by Klaus Schwab.

VIOTTI, E. B. National learning systems. A new approach on technical change in late industrializing econominies and evidences from the evidences from de the cases of Brazil and South Korea. Technological Forecasting and Social Change, v. 69, n. 7, p. 653-680, 2002. 


\section{DADOS DOS AUTORES}

\section{RAQUEL DA SILVA PEREIRA` raquelspereira@uol.com.br Doutora em Ciências Sociais pela PUC/SP}

Instituição de vinculação: Universidade Municipal de São Caetano do Sul São Caetano do Sul/SP - Brasil

Áreas de interesse em pesquisa: Desenvolvimento Sustentável, Gestão Ambiental e Sustentabilidade.

${ }^{\star}$ Rua Santo Antonio, 50, sala 221 Centro São Caetano do Sul/SP 09521-160

\section{IVALDO DONIZETI FRANCO idfranco@ig.com.br} Mestre em Administração pela USCS

Instituição de vinculação: Centro Paula Souza

São Paulo/SP - Brasil

Áreas de interesse em pesquisa: Ensino Superior, Administração e Sistemas.

\section{ISABEL CRISTINA DOS SANTOS isa.santos.sjc@gmail.com}

Doutora em Engenharia pela Escola Politécnica da USP

Instituição de vinculação: Universidade Municipal de São Caetano do Sul

São Caetano do Sul/SP - Brasil

Áreas de interesse em pesquisa: Gestão do Conhecimento, Inovação Tecnológica,

Desenvolvimento Regional e Competitividade Nacional.

\section{ALMIR MARTINS VIEIRA almir.vieira@gmail.com}

Doutor em Educação pela UNESP

Instituição de vinculação: Universidade Metodista de São Paulo

São Paulo/SP - Brasil

Áreas de interesse em pesquisa: Ensino de Administração, cultura organizacional e trabalho. 